\title{
PENGARUH KHOTBAH DALAM IBADAH MINGGU TERHADAP KEDEWASAAN IMAN JEMAAT DI GKSI MERAUKE
}

\author{
Jansakti Sadu Saly ${ }^{1}$, Hasahatan Hutahaean ${ }^{2}$ \\ Sekolah Tinggi Teologi Arastamar Merauke ${ }^{1}$, Sekolah Tinggi Teologi Sumatera Utara ${ }^{2}$ \\ salyjansaktisaddu@gmail.com
}

\begin{abstract}
This study aims to determine the effect of sermons in Sunday worship on the maturity of the congregation's faith in the Gereja Kristen Indonesia Setia (GKSI) Merauke. The method used is quantitative. The hypothesis is that there is a positive and significant influence between the sermon in Sunday worship on faith maturity. The population is the GKSI Merauke congregation, amounting to 292 people with a sample of 30 people. The instrument used was a closed questionnaire. Validity is tested using the product-moment correlation formula. Data were analyzed using the correlation technique (rxy), tested for the significant relationship with the formula (t) and the test of determination (r2), and simple regression. The successful test was tested by $F$, then to find out the effect regression equation was carried out with the formula $Y=a+b X$. The results showed the effect or $r 2=51 \%$ and significant influence or $F$ count $=28.65$ where it is known that $F$ table $=4.17$ and obtained the meaning of the simple regression equation $Y=7.25+$ $0.87 X$. This study concludes that the sermon on Sunday worship positively and significantly affects the congregation's faith maturity.
\end{abstract}

Keywords: congregation, faith maturity, Sunday sermon, GKSI

\begin{abstract}
Abstrak: Penelitian ini bertujuan untuk mengetahui pengaruh khotbah dalam ibadah Minggu terhadap kedewasaan iman jemaat di Gereja Kristen Setia Indonesia (GKSI) Merauke. Metode yang digunakan adalah kuantitatif. Hipotesisnya adalah terdapat pengaruh yang positif dan signifikan antara khotbah dalam ibadah Minggu terhadap kedewasaan iman. Populasi adalah jemaat GKSI Merauke yang berjumlah 292 orang dengan sampel 30 orang. Instrumen yang digunakan adalah angket tertutup. Kesahihan diuji dengan menggunakan rumus korelasi product moment. Data dianalisis dengan menggunakan tehnik korelasi $\left(r_{x y}\right)$, diuji signifikan hubungan dengan rumus $(t)$ dan uji determinasi $\left(r^{2}\right)$ serta regresi sederhana. Uji keberhasilan diuji dengan $F$, kemudian untuk mengetahui persamaan regresi pengaruh dilakukan dengan rumus $Y=a+b X$. Hasil penelitian menunjukkan pengaruh atau $r^{2}=51 \%$ dan signifikan pengaruh atau $\mathrm{F}$ hitung $=$ 28,65 di mana diketahui $\mathrm{F}$ tabel $=4,17$ dan memperoleh keberartian persamaan regresi sederhana $Y=7,25+0,87 X$. Penelitian ini menyimpulkan bahwa khotbah dalam ibadah Minggu berpengaruh positif dan signifikan terhadap terhadap kedewasaan iman jemaat.
\end{abstract}

Kata kunci: jemaat, kedewasaan iman, khotbah Minggu, GKSI

Pelayanan Firman telah dimulai sejak masa Perjanjian Lama (PL) hingga pada saat ini. Pada zaman PL, para nabi diutus Allah untuk 
menyampaikan pesan-pesan kepada bangsa pilihan-Nya. Penyampaian pesan tersebut merupakan sebuah pemberitaan Firman Allah (khotbah). Para nabi ini menyatakan kehendak, maksud, dan rencana Allah bagi umat-Nya untuk mendidik dan mengarahkan mereka kepada-Nya.

Dalam gereja pada umumnya, khotbah merupakan klimaks dari suatu kegiatan ibadah. Khotbah dianggap sebagai unsur yang paling penting dalam peribadatan jemaat karena dari khotbahlah jemaat mendapatkan pengertian tentang Firman Tuhan. (Conner \& Malmin, 2004). Karena itu ibadah jemaat dianggap gagal jika diselenggarakan tanpa khotbah. Khotbah diharapkan mampu menggugah, menyentuh, dan membawa jemaat beriman kepada Kristus. (Scharf, 2013).

Khotbah disampaikan dalam hampir setiap kegiatan ibadah di gereja baik ibadah Minggu, ibadah keluarga, ibadah kebangunan rohani, dll. Khotbah juga disampaikan melalui media televisi, radio, dan media lainnya. (Pasande \& Tari, 2019).

Khotbah diyakini sangat berpengaruh terhadap kedewasaan iman jemaat. Seperti dikatakan Kheng, dengan khotbah pengetahuan jemaat akan Firman Tuhan semakin bertambah dan iman mereka akan bertumbuh semakin dewasa. (Djung, 2014). Santoso, dalam penelitiannya, membuktikan bahwa pertumbuhan rohani jemaat naik 
signifikan dengan adanya khotbah yang baik dari gembala di gereja. (Santoso, 2020).

Anderson juga menguatkan hal tersebut. la mengidentifikasi bahwa khotbah memang merupakan salah satu faktor yang mempengaruhi kedewasaan iman jemaat. Khotbah di gereja adalah salah satu sarana untuk memperlengkapi orang-orang yang datang agar menjalani hidup yang benar dalam Tuhan. (Anderson, 2016).

Iman sendiri adalah penerimaan terhadap suatu kebenaran kesaksian atau keterangan orang lain tentang suatu hal meskipun belum melihatnya sendiri. Dalam bahasa Ibrani "iman" disebut dengan "aman" yang menunjukkan hubungan antara manusia dengan Tuhan. Iman adalah kepercayaan dan kesetiaan manusia kepada Tuhan. Dalam bahasa Yunani iman disebut "pitis." Kata ini mempunyai bentuk pengertian aktif dan pasif yaitu kesetiaan dan kepercayaan. Kesetiaan adalah keteguhan atau kepatuhan dan kepercayaan adalah anggapan bahwa memang benar dan dipatuhi. Dalam Ibrani 11:1 disebutkan bahwa iman adalah dasar dari sesuatu yang kita harapkan dan bukti dari sesuatu yang tidak kita lihat. Hal ini menunjukkan bahwa kedewasaan iman adalah proses yang masih berlangsung mengarah kepada keadaan atas tahap yang lebih tinggi. Efesus 4:13 menggambarkan keadaan itu dengan 
kata kedewasaan penuh dan tingkat pertumbuhan yang sesuai dengan kepenuhan Kristus (Darius \& Panggarra, 2013).

Kedewasaan iman adalah kesempurnaan dan keutuhan di dalam Kristus. Orang Kristen yang telah dewasa secara iman berarti yang telah sempurna dan tidak bercacat dalam Kristus. Hal ini juga dapat kita artikan sebagai orang yang telah mengenal Kristus dengan sepenuh hati, melalui ciptaan-Nya, melalui kasihNya, atau pengorbanan-Nya (Hutahaean, 2013).

Dalam kaitan dengan khotbah, Robinson melihat bahwa realita sekarang ini banyak pengkhotbah yang tidak berhasil mendewasakan iman jemaat. Khotbah mereka kurang diterima oleh jemaat. (Robinson dalam Arthurs, 2012). Khotbah sudah banyak disampaikan namun belum terlalu nampak realisasinya dalam kehidupan sehari-hari. Padahal dalam Roma 10:17 disebutkan bahwa iman muncul dari pendengaran akan Firman Allah, di dalamnya juga "memiliki nilai kekekalan" (Band. Banne, 2020).

Jemaat Gereja Kristen Setia Indonesia (GKSI) se-Merauke di Papua tidak jauh berbeda dengan kenyataan yang uraikan di atas. Dilihat dari keaktifan jemaat mengikuti ibadah bisa dikatakan banyak jemaat yang rajin beribadah. Berarti mereka selalu mendengarkan khotbah. Namun jika diamati dalam kehidupan jemaat sehari-hari di Merauke masih belum menunjukkan 
sebagaimana layaknya sebagai seorang Kristen yang telah bertumbuh dan dewasa dalam iman. Wawancara dengan majelis GKSI Immanuel di Tanah Merah memperkuat dugaan ini. Penelitian lainnya dari Wenggi dan Sutikto juga memberi gambaran yang serupa tentang situasi pelayanan di Papua, dari wawancara yang dilakukan terhadap gembala gereja di Papua. Perpecahan mudah terjadi dalam jemaat. Begitu juga adanya kecemburuan satu sama lain, serta malas beribadah. (Wenggi \& Sutikto, 2020).

Pertanyaannya, apakah khotbah-khotbah yang disampaikan selama ini belum berpengaruh terhadap kedewasaan iman jemaat di gereja ini? Inilah yang ingin dijawab melalui penelitian ini, sejaumana pengaruh khotbah dalam ibadah terhadap kedewasaan iman di GKSI se-Merauke. Namun mengingat banyaknya kegiatan ibadah di gereja, maka ibadah yang akan menjadi obyek penelitian adalah ibadah Minggu. Ibadah yang dilakukan pada hari Minggu ini merupakan ibadah raya di mana semua anggota jemaat hadir.

\section{METODE}

Metode yang digunakan dalam penelitian ini adalah kuantitatif. Hipotesa yang dibangun adalah ada pengaruh yang positif dan signifikan Khotbah dalam Ibadah Minggu terhadap kedewasaan Iman Jemaat di GKSI se-Merauke di Papua. Populasi dalam penelitian ini adalah seluruh 
warga jemaat di GKSI se-Merauke di Papua (Jemaat Firdaus 98 jiwa dewasa dan Immanuel Tanah Merah 184 jiwa dewasa) yang berjumlah 48 KK (total 292 Jiwa). Sehubungan dengan itu Arikunto menyatakan bahwa apabila subjeknya kurang dari 100 lebih baik diambil semua sehingga penelitiannya merupakan penelitian populasi dan selanjutnya jika jumlahnya lebih dari 100 orang, maka dapat diambil antara $10-15 \%$ atau 20- 25\% atau lebih". (Arikunto, 2012).

Mengingat banyaknya jumlah populasi dan kaitannya dengan keterbatasan waktu dan biaya dalam penelitian ini, maka peneliti mengambil sampel yang dianggap representatif untuk mewakili populasi penelitian, yaitu sebanyak $15 \%$ dari seluruh jemaat dalam hal ini adalah $15 \% \times 200$ orang adalah 30 orang.

Tabel 1. Sampel Penelitian

\begin{tabular}{|c|l|c|c|}
\hline No. & \multicolumn{1}{|c|}{ Jemaat } & $\begin{array}{c}\text { Jumlah } \\
\text { Sampel } 15 \%\end{array}$ & $\begin{array}{c}\text { Jumlah } \\
\text { Responden }\end{array}$ \\
\hline 1. & Kaum lbu & $50 \times 15 \%$ & 8 \\
\hline 2. & Kaum Bapak & $44 \times 15 \%$ & 6 \\
\hline 3. & Pemuda & $50 \times 15 \%$ & 8 \\
\hline 4. & Pemudi & $55 \times 15 \%$ & 8 \\
\hline \multicolumn{2}{|c|}{ Jumlah } & 30 orang \\
\hline
\end{tabular}

Pengambilan sampel dilakukan secara random atau acak, dalam penelitian ini penulis menyebarkan angket dengan cara mendatangi jemaat ke rumah masing-masing. 
Untuk mengumpulkan data dalam penelitian ini penulis menggunakan angket tertutup yang terdiri dari 30 pertanyaan dengan perincian 15 pertanyaan untuk variabel $\mathrm{X}$ dan 15 pertanyaan untuk variabel Y. Adapun alasan untuk mempergunakan angket tertutup adalah sesuai dengan pendapat Sugiyono yang menyatakan melalui angket tertutup akan memudahkan responden dalam mengisi jawaban, memerlukan waktu yang singkat, memusatkan perhatian responden pada pokok persoalan, relatif obyektif dan mudah ditabulasi (Sugiyono, 2018).

Tabel 2. Kisi-Kisi Angket

\begin{tabular}{|l|l|l|c|c|}
\hline No & \multicolumn{1}{|c|}{ Variabel } & \multicolumn{1}{|c|}{ Indikator } & No. Item & Jlh \\
\hline 1. & Khotbah & 1. Penjelasan inti khotbah jelas & $1,2,3$ & 3 \\
& $\begin{array}{l}\text { dalam } \\
\text { Ibadah }\end{array}$ & $\begin{array}{l}\text { 2. Ilustrasi yang diberikan dalam } \\
\text { khotbah tepat. }\end{array}$ & $4,5,6$ & 3 \\
& $\begin{array}{l}\text { Minggu } \\
(\mathrm{X})\end{array}$ & $\begin{array}{l}\text { 3. Aplikasi atau relevansi yang } \\
\text { diberikan mengena dengan } \\
\text { jemaat. }\end{array}$ & $7,8,9,10,11$ & 5 \\
& $\begin{array}{l}\text { 4. Gaya bahasa yang dipakai } \\
\text { menarik, tidak monoton. }\end{array}$ & & \\
\hline 2 & Kedewasaan & 1. Hubungan dengan Allah & $12,13,14,15$ & 4 \\
& Iman (Y) & 2. Hubungan dengan diri sendiri & $21,22,23,24$ & 4 \\
& & 3. Hubungan dalam pelayanan. & 25,26 & 2 \\
& 4. Hubungan dengan keluarga. & $27,28,29$ & 3 \\
& 5. Hubungan dengan sesama & $30,31,32,33,34,35$ & 6 \\
\hline
\end{tabular}

Rumus analisa data yang dipakai adalah;

$$
\begin{aligned}
& r_{x y}=\frac{\sum x y}{\sqrt{\left(\sum x^{2}\right)\left(\sum y^{2}\right)}} \\
& \text { di mana: } \\
& r_{x y}=\text { Koefisien korelasi } x \text { dan } y \\
& x \quad=\text { Jumlah skor rata-rata } \mathrm{x}
\end{aligned}
$$


$\mathrm{y}=$ Jumlah skor rata-rata $\mathrm{y}$

Dasar yang digunakan dalam mengolah data adalah jika koefisien $r_{\text {hitung }}$ lebih besar $(>)$ atau sama dengan $r_{\text {tabel }}$ Product Moment pada taraf $95 \%$ maka terdapat korelasi antara variabel $\mathrm{x}$ dan $\mathrm{y}$. Sebaliknya jika $r_{\text {hitung }}$ lebih kecil $(<)$ dari $r_{\text {tabel }}$ maka tidak terdapat korelasi antara variabel $x$ dan y. Sebelumnya adakan dipaparkan distribusi data tentang khotbah dalam ibadah minggu dan kedewasaan iman jemaat. Kemudian data-data itu akan diuji kesahihannya dalam validitas data dengan uji reliabilitas terhadap indeks korelasi hitung.

\section{HASIL}

Setelah angket disebar, kemudian diperoleh hasilnya seperti dalam paparan tabel berikut.

Tabel 3. Distribusi Frekuensi Jawaban Responden Tentang Khotbah Dalam Ibadah Minggu (X)

\begin{tabular}{|c|c|c|c|c|c|c|c|c|c|c|c|}
\hline \multirow{3}{*}{$\begin{array}{l}\text { No } \\
\text { Resp }\end{array}$} & \multicolumn{8}{|c|}{ Nomor Item } & \multirow{3}{*}{$\begin{array}{c}\text { Jumlah } \\
\text { Item }\end{array}$} & \multirow{3}{*}{$\begin{array}{c}\text { Jumlah } \\
\text { Score }\end{array}$} & \multirow{3}{*}{$\begin{array}{c}\text { Rata- } \\
\text { rata }\end{array}$} \\
\hline & \multicolumn{2}{|c|}{ A } & \multicolumn{2}{|c|}{ B } & \multicolumn{2}{|c|}{ C } & \multicolumn{2}{|c|}{ D } & & & \\
\hline & $F$ & Sc & $F$ & Sc & $\mathrm{F}$ & $\mathrm{Sc}$ & $F$ & $\mathrm{Sc}$ & & & \\
\hline 1 & 23 & 92 & 2 & 6 & 4 & 8 & 1 & 1 & 30 & 107 & 3.57 \\
\hline 2 & 11 & 44 & 5 & 15 & 13 & 26 & 1 & 1 & 30 & 86 & 2.87 \\
\hline 3 & 25 & 100 & 3 & 9 & 2 & 4 & 0 & 0 & 30 & 113 & 3.77 \\
\hline 4 & 5 & 20 & 2 & 6 & 19 & 38 & 4 & 4 & 30 & 68 & 2.27 \\
\hline 5 & 14 & 56 & 4 & 12 & 9 & 18 & 3 & 3 & 30 & 89 & 2.97 \\
\hline 6 & 15 & 60 & 4 & 12 & 11 & 22 & 0 & 0 & 30 & 94 & 3.13 \\
\hline 7 & 9 & 36 & 4 & 12 & 15 & 30 & 2 & 2 & 30 & 80 & 2.67 \\
\hline 8 & 9 & 36 & 5 & 15 & 7 & 14 & 9 & 9 & 30 & 74 & 2.47 \\
\hline 9 & 10 & 40 & 9 & 27 & 10 & 20 & 1 & 1 & 30 & 88 & 2.93 \\
\hline 10 & 4 & 16 & 7 & 21 & 15 & 30 & 4 & 4 & 30 & 71 & 2.37 \\
\hline 11 & 20 & 80 & 5 & 15 & 4 & 8 & 1 & 1 & 30 & 104 & 3.47 \\
\hline 12 & 18 & 72 & 8 & 24 & 4 & 8 & 0 & 0 & 30 & 104 & 3.47 \\
\hline 13 & 9 & 36 & 8 & 24 & 9 & 18 & 4 & 4 & 30 & 82 & 2.73 \\
\hline
\end{tabular}




\begin{tabular}{|c|c|c|c|c|c|c|c|c|c|c|c|}
14 & 21 & 84 & 5 & 15 & 4 & 8 & 0 & 0 & 30 & 107 & 3.57 \\
\hline 15 & 16 & 64 & 9 & 27 & 4 & 8 & 1 & 1 & 30 & 100 & 3.33 \\
\hline \multicolumn{10}{|c|}{ Jumlah } \\
\hline \multicolumn{11}{|c|}{ Jumlah Rata-rata } & 3.04 \\
\hline
\end{tabular}

Tabel 4. Distribusi Frekuensi Jawaban Responden Tentang Kedewasaan Iman Jemaat $(\mathrm{Y})$

\begin{tabular}{|c|c|c|c|c|c|c|c|c|c|c|c|}
\hline \multirow{3}{*}{$\begin{array}{c}\text { No } \\
\text { Resp }\end{array}$} & \multicolumn{8}{|c|}{ Nomor Item } & \multirow{3}{*}{$\begin{array}{c}\text { Jumlah } \\
\text { Item }\end{array}$} & \multirow{3}{*}{$\begin{array}{c}\text { Jumlah } \\
\text { Score }\end{array}$} & \multirow{3}{*}{ Rata-rata } \\
\hline & \multicolumn{2}{|c|}{$A$} & \multicolumn{2}{|c|}{$\mathrm{B}$} & \multicolumn{2}{|c|}{ C } & \multicolumn{2}{|c|}{$\mathrm{D}$} & & & \\
\hline & $\mathrm{F}$ & Sc & $\mathrm{F}$ & Sc & $F$ & Sc & $\mathrm{F}$ & Sc & & & \\
\hline 16 & 11 & 44 & 7 & 21 & 12 & 24 & 0 & 0 & 30 & 89 & 2.97 \\
\hline 17 & 20 & 80 & 5 & 15 & 5 & 10 & 0 & 0 & 30 & 105 & 3.50 \\
\hline 18 & 15 & 60 & 7 & 21 & 4 & 8 & 4 & 0 & 30 & 89 & 2.97 \\
\hline 19 & 12 & 48 & 10 & 30 & 8 & 16 & 0 & 0 & 30 & 94 & 3.13 \\
\hline 20 & 7 & 28 & 10 & 30 & 12 & 24 & 1 & 1 & 30 & 83 & 2.77 \\
\hline 21 & 12 & 48 & 5 & 15 & 2 & 4 & 11 & 11 & 30 & 78 & 2.60 \\
\hline 22 & 15 & 60 & 8 & 24 & 7 & 14 & 0 & 0 & 30 & 98 & 3.27 \\
\hline 23 & 14 & 56 & 9 & 27 & 7 & 14 & 0 & 0 & 30 & 97 & 3.23 \\
\hline 24 & 15 & 60 & 9 & 27 & 5 & 10 & 1 & 1 & 30 & 98 & 3.27 \\
\hline 25 & 2 & 8 & 2 & 6 & 12 & 24 & 14 & 14 & 30 & 52 & 1.73 \\
\hline 26 & 18 & 72 & 5 & 15 & 7 & 14 & 0 & 0 & 30 & 101 & 3.37 \\
\hline 27 & 18 & 72 & 8 & 24 & 4 & 8 & 0 & 0 & 30 & 104 & 3.47 \\
\hline 28 & 22 & 88 & 3 & 9 & 3 & 6 & 2 & 2 & 30 & 105 & 3.50 \\
\hline 29 & 20 & 80 & 1 & 3 & 9 & 18 & 0 & 0 & 30 & 101 & 3.37 \\
\hline 30 & 23 & 92 & 6 & 18 & 1 & 2 & 0 & 0 & 30 & 112 & 3.73 \\
\hline & & & & & mlah & & & & & 1406 & 46.87 \\
\hline & & & & & umla & 110 & at & & & & 3.12 \\
\hline
\end{tabular}

Dari distribusi frekuensi data di atas, validitas yakni kesahihannya akan ditunjukkan dalam tabel berikut.

Tabel 5. Validitas Perbandingan $r$ hitung dengan $r$ table

\begin{tabular}{|c|c|c|c|}
\hline No Item & $r$ hitung & $r$ tabel & Keterangan \\
\hline 1 & 0.938 & 0,765 & Valid \\
\hline 2 & 0.902 & 0.765 & Valid \\
\hline 3 & 0.981 & 0,765 & Valid \\
\hline 4 & 0.998 & 0.765 & Valid \\
\hline 5 & 0.993 & 0,765 & Valid \\
\hline 6 & 0.987 & 0.765 & Valid \\
\hline 7 & 0.969 & 0,765 & Valid \\
\hline
\end{tabular}




\begin{tabular}{|c|c|c|c|}
\hline 8 & 0.981 & 0.765 & Valid \\
\hline 9 & 0.948 & 0,765 & Valid \\
\hline 10 & 0.971 & 0.765 & Valid \\
\hline 11 & 0.956 & 0,765 & Valid \\
\hline 12 & 0.939 & 0.765 & Valid \\
\hline 13 & 0.872 & 0,765 & Valid \\
\hline 14 & 0.966 & 0.765 & Valid \\
\hline 15 & 0.994 & 0,765 & Valid \\
\hline 16 & 0,969 & 0,632 & Valid \\
\hline 17 & 0,955 & 0,632 & Valid \\
\hline 18 & 0,995 & 0,632 & Valid \\
\hline 19 & 0,942 & 0,632 & Valid \\
\hline 20 & 0,942 & 0,632 & Valid \\
\hline 21 & 0,953 & 0,632 & Valid \\
\hline 22 & 0,969 & 0,632 & Valid \\
\hline 23 & 0,995 & 0,632 & Valid \\
\hline 24 & 0,950 & 0,632 & Valid \\
\hline 25 & 0,961 & 0,632 & Valid \\
\hline 26 & 0,970 & 0,632 & Valid \\
\hline 27 & 0,958 & 0,632 & Valid \\
\hline 28 & 0,954 & 0,632 & Valid \\
\hline 29 & 0,957 & 0,632 & Valid \\
\hline 30 & 0,951 & 0,632 & Valid \\
\hline 31 & 0,986 & 0,632 & Valid \\
\hline 32 & 0,951 & 0,632 & Valid \\
\hline 33 & 0,945 & 0,632 & Valid \\
\hline 34 & 0,962 & 0,632 & Valid \\
\hline 35 & 0,947 & 0,632 & Valid \\
\hline & & & \\
\hline
\end{tabular}

Berdasarkan data yang terdapat dapada tabel di atas, ternyata ke 35 item yang terdapat dalam angket menunjukkan kesahian yang tinggi. Dengan demikian angket dipergunakan untuk mengumpulkan data.

Selanjutnya harga $r 11$ yang diperoleh yaitu untuk variable $(X)$ 0,797 dan untuk variable $(Y)$ 0,726 dikonsultasikan dengan indeks korelasi hitung dengan implementasi sederhana yang dibuat Arikunto (Arikunto, 2012) yaitu: $0,800-1,000=$ Sangat Tinggi, $0,600-0,799=$ Tinggi, 0,400 
- 0,599 = Cukup, $0,200-0,399=$ Rendah, dan $0,000-0,199=$ Sangat Rendah

Dengan mengonsultasikan ke dalam indeks korelasi sederhana yang dibuat oleh Arikunto (Arikunto, 2012) ternyata harga $r 11=$ variable (X) 0,797 dan untuk variable (Y) 0,726 terdapat pada korelasi tinggi yaitu pada 0,600 - 0,799. Dengan demikian angket pengaruh Khotbah Dalam Ibadah Minggu dan Pengaruhnya Terhadap Kedewasaan Iman Jemaat di GKSI Merauke adalah reliable untuk digunakan.

Analisis regresi linier sederhana digunakan untuk mengetahui hubungan fungsional antara variabel $X$ dan Variabel $Y$ yaitu dengan menggunakan rumus $\hat{Y}=a+b X$. Dengan demikian maka harga $\hat{Y}=$ $a+b X$. Adalah $\hat{Y}=7,25+0,87 X$. artinya adanya hubungan fungsional antara kedua variabel.

Dengan demikian hipotesis yang mengatakan Khotbah dalam ibadah minggu mempunyai pengaruh yang positif dan signifikan terhadap Kedewasaan Iman di GKSI se-Merauke di Papua Tahun 2019 dapat diterima kebenarannya. Nilai yang didapat tersebut lalu dimasukkan ke dalam tabel berikut untuk mengetahui apakah terdapat pengaruh yang positif dan signifikan khotbah dalam ibadah Minggu terhadap kedewasaan iman jemaat GKSI se-Merauke.

Tabel 6. Daftar Hasil Perhitungan Analisis Untuk Regresi Linier Sederhana

\begin{tabular}{l|l|l|l|ll|}
\hline Sumber Variasi & dk & Jk & KT & F & \\
\hline Jansakti Sadu Saly, Hasahatan Hutahaean & \multicolumn{2}{|c|}{235}
\end{tabular}




\begin{tabular}{|l|l|l|l|l|}
\hline Total & 30 & 66828 & 66828 & - \\
\hline Regresi (a) & 1 & 66270 & 66270 & \\
\hline Regresi (b/a) & 1 & 281,88 & 281,88 & 28,65 \\
\hline Residu & 28 & 275,67 & 9,84 & \\
\hline Tuna cocok & 11 & 499,2 & 7,647 & 0,654 \\
\hline Kekeliruan & 17 & 360,68 & 11,676 & \\
\hline
\end{tabular}

Dari tabel perhitungan diatas diperoleh $\mathrm{F}$ hitung sebesar 28,65 dan dikonsultasikan degan $\mathrm{F}$ tabel $0,05=4,17$, ternyata $\mathrm{F}$ hitung $>\mathrm{F}$ tabel $(28,65>4,17)$.

Hasil anava tersebut menyimpulkan bahwa terdapat pengaruh yang positif dan signifikan antara khotbah dalam ibadah Minggu terhadap kedewasaan iman jemaat di GKSI se-Merauke di Papua Tahun 2019 pada taraf $\square=0,05$. Untuk menguji hipotesa digunakan ketentuan sebagai berikut: ada pengaruh yang positif dan signifikan apabila $\mathrm{Ha}=\mathrm{Fh}>\mathrm{Ft}$; 0,05 artinya dapat diterima $\mathrm{Ho}-\mathrm{Fh}<\mathrm{ft} ; 0,05$ artinya ditolak.

Dari penghitungan uji $F$, maka diperoleh $F$ hitung $28,56>F$ tabel 4,17 artinya bahwa terdapat pengaruh yang positif dan signifikan antara Khotbah dalam ibadah minggu terhadap Kedewasaan Iman Jemaat di GKSI se-Merauke di Papua, sehingga hipotesa nihil (Ho) ditolak dan hipotesis yang berbunyi ada pengaruh khotbah dalam ibadah minggu terhadap kedewasaan Iman jemaat di GKSI se-Merauke di Papua Tahun 2019" dapat diterima kebenarannya, karena telah terbukti secara empiris pada $\square=0,05$. 


\section{PEMBAHASAN}

Hasil yang ditemukan dalam penelitian ini seperti diuraikan di atas menjelaskan bahwa khotbah-khotbah yang disampaikan dalam ibadah Minggu belum berpengaruh secara signifikan bagi kedewasaan iman jemaat di GKSI Merauke. Hal ini didukung dengan fakta bahwa masih banyak anggota jemaat yang hidup dalam kedagingan seolah-olah mereka tidak mempunyai tujuan hidup dan tidak punya pengharapan. Ada jemaat yang hanya bersandar kepada pengertiannya sendiri dan mengandalkan kemampuan sendiri. Artinya khotbah-khotbah yang sudah banyak disampaikan kepada mereka belum mampu mendorong mereka berubah dan bertumbuh dalam kedewasaan iman.

Asrilita mengemukakan bahwa khotbah memiliki tiga unsur utama yaitu pengkhotbah, pesan, dan pendengar. (Asrilita, 2019). Ketiga unsur ini merupakan satu kesatuan jika dilihat dari posisi gereja sebagai penanggungjawab penyampaikan khotbah. Pengkhotbah yang baik akan menghasilkan pesan yang baik yang bisa membawa dampak positif bagi kedewasaan iman jemaat. Begitu juga sebaliknya.

Salong dan Ronda dalam penelitian mereka menemukan bahwa jemaat berharap khotbah itu,

dapat menyentuh kebutuhan hidupnya, menyentuh hatinya, agar setiap jemaat mendapatkan pemulihan, bersedia meninggalkan kehidupan yang lama dan menjalani kehidupan yang baru, 
kehidupan yang dekat dengan Tuhan, dan kehidupan yang dapat menjadi saksi, kesaksian bagi orang lain. Agar melalui hidupnya itu, orang lain dapat mengenal dan menerima Yesus sebagai Tuhan dan juruselamatnya secara pribadi. (Salong \& Ronda, 2012, hal. 198).

Dengan mendengar pendeta berkhotbah jemaat mempunyai orientasi yang baru dalam kaitan memberi penguatan terhadap identitas kekristenannya ke arah yang lebih bertanggung jawab serta menimbulkan kontemplasi personal yang lebih intens. (Rey, 2016).

Sebab itu pengkhotbah yang baik haruslah mengenal dirinya sendiri dengan baik, mengenal lingkungan di sekitar terutama kehidupan pendengar khotbahnya, dan merupakan panutan bagi orang-orang di sekitarnya. (Asrilita, 2019). la memiliki hubungan baik dengan pendengar khotbahnya. Hutahaean mengatakan, selalu ada kesempatan tegur sapa satu dengan yang lain untuk pertumbuhan iman bersama. (Hutahaean, 2014). Pengkhotbah tidak bisa hanya mengandalkan interaksi dengan jemaat dari atas mimbar namun harus didukung performa di luar mimbar.

Selain itu, seorang pengkhotbah harus memiliki kerohanian atau spritualitas yang baik. Hengki Wijaya mengatakan bahwa seorang pengkhotbah harus memiliki waktu dan jadwal berduaan dengan Tuhan dan firman-Nya. Pengkhotbah perlu mengetahui isi hati Tuhan bagi jemaat-Nya.(Wijaya, 2018). Artinya, pengkhotbah harus memiliki relasi yang sangat intens dan personal dengan Tuhan. Apa yang disampaikan 
melalui khotbah kepada jemaat haruslah benar-benar berasal dari Tuhan. Seperti dikatakan Santoso, agar apa yang disampaikannya merupakan konsep, tujuan, pemikiran yang sepenuhnya dari Allah. (Santoso, 2020).

Seorang pengkhotbah dituntut untuk profesional dalam berkhotbah. Salah satunya adalah ia harus memiliki kemampuan berkomunikasi yang baik (Hulst, 2018), termasuk menggunakan media yang tepat. (Salong \& Ronda, 2012). Dengan demikian diharapkan para pendengar tertarik untuk mendengar dan melakukannya.

Pengkhotbah adalah seorang hamba Allah yang dipilih-Nya untuk tugas khusus ini. Apa yang disampaikannya harus bersumber dari Firman Allah yaitu seperti yang tertulis dalam Alkitab. Dengan tegas Mantiri menyatakan bahwa suatu khotbah dibuat hanya berdasarkan Alkitab yang sudah diwahyukan Allah. Alkitab perlu dipahami melalui proses penafsiran-penafsiran, sebaiknya bukanlah suatu usaha menduga-duga apa yang ditulis dalam Alkitab. Seorang penafsir menggunakan prinsip dan metode penafsiran yang dapat dipertanggung jawabkan. Dalam proses penafsiran seorang pengkhotbah perlu mengandalkan pertolongan Allah (Mantiri, 2019), sehingga berkhotbah, bukan hanya melibatkan teknik komunikasi. Yang lebih penting isi khotbah merupakan penyampaian ajaran Alkitab yang 
diimani pengkhotbah. Dengan demikian kehendak Tuhan yang disampaikan jelas kepada para pendengar.

Di atas semuanya itu, tentu adalah peran Roh Kudus. Roh Kuduslah yang mengubah kata-kata manusia menjadi sabda Tuhan dalam telinga dan hati pendengar. Kata-kata dalam khotbah bukanlah Wahyu khusus yang setara dengan Alkitab. Dalam pandangan evangelikal, kesatuan pemberitaan firman di ibadah, pelayanan sakramen harus dikaitkan dengan kehadiran Roh Kudus (Smith, 2019). Hal ini perlu terus dikaitkan agar gereja tidak kehilangan daya dorong spiritualitasnya.

Terkait dengan hasil penelitian di GKSI Merauke ini, maka tampaknya, secara teoretis, permasalahan kurangnya pengaruh khotbah dalam ibadah terhadap kedewasaan iman jemaat ada di seputar pengkhotbah. Masalah tersebut bisa karena masalah kehidupan spiritual dan keteladanan di hadapan jemaat. Bisa juga karena kurangnya kemampuan memahami kondisi kehidupan jemaat sehingga memberikan jawaban melalui khotbah. Selebihnya, bisa karena kurangnya kemampuan menyampaikan khotbah yang komunikatif sehingga mampu menyentuh hati jemaat dan memotivasi mereka untuk berubah.

Namun demikian, tentu saja hal tersebut perlu dibuktikan melalui penelitian lanjutan. Penelitian ini terbatas untuk membuktikan adakah pengaruh khotbah Minggu terhadap kedewasaan iman jemaat. Khotbah seharusnya berpengaruh terhadap kedewasaan iman jemaat. 
Namun jika masih banyak anggota jemaat yang belum dewasa imannya, maka berarti khotbah yang disampaikan belum banyak berhasil memotivasi atau mendorong jemaat untuk bertumbuh imannya menuju kedewasaan.

Penelitian lanjutan perlu dilakukan untuk variabel yang lebih luas dan penelusuran fakta di lapangan atau literatur yang lebih mendalam. Peneliti terbatas akan waktu dalam menjangkau jemaat GKSI Digoel, yang jauh dari kedudukan di Merauke. Keterbatasan dari sisi mengumpulkan angket agar menjadi perhatian bagi peneliti lanjutan lainnya.

\section{KESIMPULAN}

Khotbah dalam ibadah-ibadah di gereja mestinya berpengaruh positif bagi pertumbuhan kedewasaan iman jemaat. Apabila iman jemaat pada umumnya belum menunjukkan kedewasaan maka tentu ada hal penting yang perlu dibenahi dalam penyampaikan khotbah di gereja, khususnya dalam ibadah Minggu. Pengkhotbah merupakan unsur penting dalam khotbah. Kehidupan pribadinya, spiritualitasnya, relasinya dengan pendengar, kemampuannya berkomunikasi, dan hal lain yang terkait dengan itu, perlu untuk terus dikembangkan.

Bagaimanapun kedewasaan iman jemaat merupakan impian banyak gembala sidang atau pendeta jemaat di manapun melayani. Sebaliknya jemaat merindukan kedewasaan iman dari tuntunan Hamba 
Tuhan, salah satunya mendengar berita Firman TUHAN di ibadah Minggu. Kedewasaan iman meliputi banyak aspek dalam kehidupan, dua di antaranya adalah mempersiapkan diri mendengar Firman dan siap berubah atas dasar Firman yang didengar. Jemaat ingin kedewasaan iman ini juga berdampak bagi kehidupan sehari hari dalam berpikir, bertindak dan berperilaku di mana saja.

Hasil penelitian di GKSI Merauke ini kiranya memberikan kontribusi bagi pengembangan pelayanan di gereja ini dan juga bagi gereja-gereja lain di mana pun juga.

\section{DAFTAR PUSTAKA}

Anderson, N. T. (2016). Menjadi Gereja Pembuat Murid. Yayasan Gloria.

Arikunto, S. (2012). Prosedur Penelitian: Suatu Pendekatan Praktik (Edisi Revisi). In Rineka Cipta (Revisi). PT. Rineka Cipta.

Arthurs, J. D. (2012). Preaching With Variety: Bagaimana Menciptakan Ulang Genre Biblika Yang Dinamis. Literatur SAAT.

Asrilita, T. (2019). Studi Homiletika Pengaruh Pengkhotbah Tamu Dalam Pertumbuhan Iman di JKI Immanuel Kudus. Universitas Kristen Satya Wacana Salatiga.

Banne, E. (2020). Menerapkan Makna Ibadah Menurut 1 Timotius bagi Jemaat Gereja Pantekosta di Indonesia Hosana, Keerom Barat, Papua. EPIGRAPHE: Jurnal Teologi dan Pelayanan Kristiani, 4(1), 57-70. https://doi.org/10.33991/epigraphe.v4i1.151

Conner, K. J., \& Malmin, K. (2004). Interpreting The Scripture. Gandum Mas.

Darius, D., \& Panggarra, R. (2013). Konsep Manusia Baru Berdasarkan Perspektif Paulus Dalam Efesus 4:17-32 Dan Implementasinya Dalam Kehidupan Orang Percaya. Jurnal Jaffray, 11(2), 29-58. https://doi.org/10.25278/jj71.v11i2.80 
Djung, P. K. H. (2014). Belajar Dari Bapa Gereja Agustinus: Sebuah Pendekatan Terhadap Khotbah Doktrin Trinitas. VERITAS, 15 (1), 120.

Hulst, M. S. (2018). Pedoman Khotbah Lengkap: Sepuluh Cara Praktis Untuk Khotbah Yang Lebih Baik. Waskita Publishing.

Hutahaean, H. (2014). Peran Gereja Di Tengah Masyarakat Kota. Didaskein, 2(1), 7-16.

Hutahaean, H. (2013). Implementasi Keyakinan Telah Diselamatkan. In G. Ginting, T. P. Tarigan, \& H. Hutahaean (Ed.), Soteriologi Biblika (hal. 41-56). Prodi Teologi STTSU.

Mantiri, L. G. (2019). Pentingnya Komunikasi dalam Penafsiran Alkitab. BIA': Jurnal Teologi dan Pendidikan Kristen Kontekstual, 2(1), 108120. https://doi.org/10.34307/b.v2i1.75

Pasande, P., \& Tari, E. (2019). Peran Gereja Dalam Pengembangan Program Kewirausahaan Di Era Digital. Visio Dei: Jurnal Teologi Kristen, 1(1), 38-58.

Rey, K. T. (2016). Khotbah Pengajaran Versus Khotbah Kontemporer. Dunamis, 1(1), 31-54. https://doi.org/10.30648/dun.v1i1.100

Salong, Y., \& Ronda, D. (2012). Analisis Peran Teori Komunikasi Untuk Mencapai Tujuan Khotbah Yang Komunikatif Di Gereja Kibaid Klasis Makassar. Jurnal Jaffray, 10(1), 174-201.

Santoso, D. S. B. (2020). Peran Khotbah Gembala Sidang dalam Pertumbuhan Rohani Jemaat. Magnum Opus Jurnal Teologi dan Kepemimpinan Kristen, 1(2), 88-97.

Scharf, G. (2013). Khotbah Yang Transformatif. Yayasan Komunikasi Bina Kasih.

Smith, G. T. (2019). Evangelikal, Sakramental dan Pentakostal Sifat dan Praktik Gereja Seharusnya. Indonesia Cahaya Rahmat Empati.

Sugiyono, S. (2018). Metode Penelitian Kuantitatif. AlfaBeta.

Wenggi, D., \& Sutikto, S. (2020). Prinsip Penggembalaan Menurut 1 Timotius 4:1-16: Kajian Reflektif untuk Penerapan di GPdl Wilayah Waropen Barat, Papua. EPIGRAPHE: Jurnal Teologi dan Pelayanan Kristiani, 4(1), 31-43. https://doi.org/10.33991/epigraphe.v4i1.

Wijaya, H. (2018). Khotbah Untuk Pendidikan Warga Jemaat. Sekolah Tinggi Theologia Jaffray. 